\title{
Örgütsel Sinizm, Zorunlu Örgütsel Vatandaşlık Davranışları ve İş Tatmininin Bireysel İş Performansına Etkilerinin Belirlenmesine Yönelik İmalat Sanayide Bir Uygulama
}

\author{
Mustafa Kemal TOPCU* Memduh BEĞENIRBAŞ ${ }^{* *}$ Ercan TURGUT****
}

$\ddot{O} Z$

$B u$ çalışmada, zorunlu örgütsel vatandaşlık davranışl, örgütsel sinizm ve iş tatmininin çalışanların bireysel iş performanslarına olan etkileri araştırılmıştır. Çalışma, Ankara Sanayi Odasına üye firmalarda çalı̧̧an ve belli bir eğitim almak üzere bir araya gelmiş 138 bireyden toplanan veri üzerinden gerçekleştirilmiştir. Değişkenler arası ilişkiler korelasyon, etkiler ise regresyon analizleri ile ortaya konurken, değişkenlere ait ölçeklerin geçerlik çalışması için doğrulayıcı faktör analizi kullanılmıştır. Elde edilen bulgular, genel olarak zorunlu örgütsel vatandaşlık davranışının ve örgütsel sinizmin çalışanların performanslarl üzerinde negatif, iş tatminlerinin ise pozitif etkileri olduğunu göstermektedir.

Anahtar Kelimeler: Zorunlu Örgütsel Vatandaşlık Davranışı, Örgütsel Sinizm, İş Tatmini, Bireysel Işs Performansı

JEL Sinıflandırması: M12, M14, M19

A Study in Manifacturing Industry to Determine the Effects of Organizational Cynicism, Compulsory Organizational Citizenship Behavior and Job Satisfaction on Individual Work Performance

\begin{abstract}
This study researches effects of compulsory organizational citizenship behavior, organizational cynicism, and job satisfaction on employees' individual work performance. The study employs data collected from 138 trainees working in the manifacturing firms, which are members of Ankara Chamber of Industry. Correlation analysis and regression analysis are conducted to determine the relations and the effects between the variables, relatively, whilst confirmatory factor analysis is preferred for validating scales. Findings reveal that there is a negative effect of compulsory organizational citizenship behavior and organizational cynicism on individual work performance while the effect of job satisfaction is positive.
\end{abstract}

Key Words: New Tourist, Compulsory Organizational Citizenship Behavior, Organizational Cynicism, Job Satisfaction, Individual Work Performance

JEL Classification: M12, M14, M19

\section{GİRIŞ̧}

Günümüzde iş yaşamının niteliği ve hızlı değişimi örgütlerin üzerinde büyük bir baskı oluşturmaktadır. Bu baskı yöneticilerin ve çalışanların sahip

\footnotetext{
* Dr. Fokus Yaşam Akademisi topcumustafakemal@yahoo.com

** Dr. Kara Kuvvetleri Komutanlığı mbegenirbas@yahoo.com

** Dr. Kara Kuvvetleri Komutanlığı ercanturg@gmail.com
} 
M. K. Topcu, M. Beğenirbaş \& E. Turgut / Örgütsel Sinizm, Zorunlu Örgütsel Vatandaşllk Davranışlart ve İs Tatmininin Bireysel I̦S Performansına Etkilerinin Belirlenmesine Yönelik İmalat Sanayide Bir Uygulama

olması gereken bilgi, beceri ve yeteneklerinin artarak çeşitlenmesine neden olmakta ve bu durum da çalışanlardan beklenen iş performansının yükselmesi olarak yansımaktadır. Önümüzdeki yıllarda da çalışanlardan yüksek düzeyde performans beklentisinin devam edeceği düşünülmektedir. Dolayısıyla çalışanların performanslarının artmasında rol oynayan tüm faktör ve değişkenlerin en uygun şekilde örgüt yapısında ve işleyiş̧inde yer almasını sağlamak örgütsel başarı için bir zorunluluk haline gelmektedir. Bu kapsamda bireysel iş performans1, örgütlerin üzerinde özenle durduğu ana konulardan birisi olarak seçim aşamasından işten ayırmaya kadar insan kaynakları uygulamalarının tamamında belirleyici bir rol oynamaktadır (Viswesvaran ve Önes, 2000).

Bireysel iş performansı alanyazında sıklıkla araştırılan bir konu olmuştur. Bir sonuç değişkeni olarak ele alınan bireysel iş performansının öncülü olarak kişilik (Barrick ve Mount, 1991; Tett vd., 1991; Hurtz ve Donovan, 2000; Wang, 2011; Judge vd., 2013; Muldoon vd., 2017), duygu durumu (Cropanzano vd., 1993; Kaplan vd., 2009), öz değerlendirme (Kacmar vd., 2009), yaratıc1lı (Charbonnier-Voirin ve Roussel, 2012), psikolojik sermaye (Peterson vd., 2011) ve duygusal zeka (Cote ve Miners, 2006) gibi bireysel faktörlere, işe bağlanma (Rich vd., 2010; Coffeng vd., 2014), örgütsel adalet (Konovsky ve Cropanzano, 1991; Colquitt vd., 2013; Shan vd., 2015; Wang vd., 2015), duygusal tükenme (Wright ve Cropanzano, 1998; Wright ve Hobfoll, 2004), üretkenlik karşı1tı davranışlar (Sackett, 2002; Koopmans vd., 2014; Macovei, 2016) ve iş tatmini (Iaffaldano ve Muchinsky, 1985; Judge vd., 2009; Kaleem vd., 2013) gibi örgütsel faktörlere ilişkin çalışmalar bulunmaktadır. Ancak örgütsel davranış alanyazınında yakın zamanlarda çalışılmaya başlanan konulardan zorunlu vatandaşlık davranışı ve örgütsel sinizmin bireysel iş performansını ne şekilde etkilediğine yönelik çalışmalara rastlanmamaktadır. Bu sebeple, bu çalışma Ankara Sanayi Odasına üye firmalarda çalışanlardan oluşan bir örneklemde bireysel iş performansının öncülü olarak zorunlu örgütsel vatandaşlık davranışı ve örgütsel sinizm ile birlikte iş tatmininin etkisinin belirlenmesi maksadıyla tasarlanmıştır. $\mathrm{Bu}$ amaçla değişkenlerin bireysel iş performansı üzerindeki etkisinin ortaya konması için korelasyon ve regresyon analizi yapılarak, elde edilen bulgular tartışılmıştır. Bu çerçevede çalışmada öncelikle değişkenler arasındaki ilişkiler kuramsal olarak incelenmekte ve hipotezler üretilmektedir. Daha sonra bu hipotezler test edilerek bulgular elde edilmekte ve araştırmac1, akademisyen, uzman, yönetici ve çalışanlara bazı ipuçları sunacak çıkarımlarda bulunulmaktadir.

\section{KAVRAMSAL ÇERÇEVE}

\section{A. Bireysel İş Performansı}

Bireysel iş performansı, örgütlerde belirli bir amacın, fonksiyonun veya görevin yürütülmesiyle ya da gerçekleştirilmesiyle ilişkili bir kavram olarak karşımıza çıkmaktadır (Borman ve Motowidlo, 1993). Bireysel iş performansı 
örgütsel amaçlara yönelik niyet ve davranışların tamamı olarak düşünülebilir (Koopmans vd., 2014). Bireysel iş performansı çok özet bir şekilde bireyin işini yerine getirmek için harcamış olduğu gayretin tamamı karşılığında elde ettiği başarı düzeyi olarak tanımlamak mümkündür. Buradan anlaş1lacağ 1 gibi bireysel iş performans1, bireyin sahip olduğu nitelikler ve yetenekler ile inanç ve değerlerine doğrudan bağlıdır (Morillo, 1990).

Alanyazında bireysel iş performansına yönelik farklı tanımlara rastlamak mümkündür. Charbonnier-Voirin ve Roussel (2012) bireysel iş performansını sadece sonuçlara endeksli bir kara kutu olarak tarif ederken, Rousseau ve McLean (1993) bireysel iş performansını çalışanların ücret karşıllı̆ıında sarf etmeleri gereken gayret olarak nitelendirmekte, Kohli (1985) çalışanın kendine eşdeğer çalışanlara kıyasla iş ile ilgili davranış ve çıktılarının verimlilik düzeyi olarak tanımlamaktadır. Bireysel iş performansı, çalışanın organizasyonun hedeflerine ulaşmasına katkıda bulunmak için yaptığı ve kontrol edebildiği her türlü faaliyet ve davranış şeklinde de ele alınmaktadır (Rotundo ve Sackett, 2002).

Bireysel iş performansının iş odaklı yetkinlik, genel yetkinlik, iletişim becerileri, gayret gösterme, özdisiplin, ekip çalışması yapabilme, liderlik ve yönetim olmak üzere sekiz faktörden oluştuğu ifade edilmektedir (Campbell ve ark., 1993). Bu çalışma kapsamında bireysel iş performansı iş odaklı yetkinlik temelinde el alınmaktadır. Nitekim Borman ve Motowidlo (1993) bireysel iş performansını temel iş gereksinimleri ile ilişkilendirmekte ve örgütlerin teknik yetkinliklerine katkı sağlaması gerektiğini düşünmektedir. Diğer bir ifade ile bireysel iş performansının çalışanın görev tanım formunda yer alan kriterleri karşılayıp karşılamadığına ilişkin bir değerlendirme olduğunu ifade etmek mümkündür (Bergeron vd., 2013:959). Buradan hareketle, bireysel iş performansının gözlemlenebilir ve ölçülebilir bireysel yetkinlikler ile birlikte örgüte sağlanan katkılar olduğu sonucuna varılabilir (Campbell vd., 1993). Nitekim çalışan bireysel iş performansı ile işini anlamlandırırken, bireysel iyilik halini olumlamakta ve çalışma arkadaşları başta olmak üzere çevresini de olumlu yönlendirmektedir (Pradhan ve Jena, 2017).

\section{B. Zorunlu Örgütsel Vatandaşlık Davranışının Bireysel İş Performansı ile İlişsisi}

Örgütsel vatandaşlık davranışı (ÖVD) bireysel tercihe bağlı olan ve örgütsel süreçler tarafından tanınmayan ancak örgütsel performansa olumlu katkısı bulunan ekstra rol davranışlarıdır (Organ, 1988:4). Şüphesiz ÖVD’lerin örgüt genelinde çalışanların tamamında görülmesi halinde örgütsel etkililik de artmaktadır (Organ ve Konovsky, 1989). Bu hali ile ÖVD alanyazını ağırlıklı olarak ÖVD'nin örgütsel performansa ve işyerindeki sosyal iklime olan katkısı üzerine eğilmektedir. Bu doğrultuda ÖVD'nin örgütler için arzu edilen pozitif bir örgütsel davranış olduğu ifade edilebilir.

Diğer taraftan, son dönemlerde alanyazında "Acaba rol ötesi davranışlar belirli bir düzeyden sonra örgüt ve çalışan açısından olumsuzluklar yaratabilir mi?” sorusu tartış1maya başlanmıştır (Porpara, 1989; Vigoda- Gadot, 2006). 
M. K. Topcu, M. Beğenirbaş \& E. Turgut / Örgütsel Sinizm, Zorunlu Örgütsel Vatandaşllk Davranışlart ve İs Tatmininin Bireysel I̦S Performansına Etkilerinin Belirlenmesine Yönelik İmalat Sanayide Bir Uygulama

Benzer şekilde "Çalışanların sergilemiş olduğu diğergamlık, nezaket, centilmenlik, vicdanlılık ve sivil erdem gibi rol ötesi davranışlar acaba zamanla yöneticiler tarafından çalışanın iş tanımı içerisinde değerlendirilebilir mi?" sorusu da akla gelmektedir. İşte bu sorular ÖVD'nin karanlık yönlerinin bulunduğuna işaret ederek, iyi yönetilemeyen ÖVD'nin günümüz rekabet koşullarının da vermiş olduğu bir alg1 ile zorunluluk haline dönüşebileceğini göstermektedir (Vigoda-Gadot, 2006:78).

Yöneticiler ve çalışma arkadaşlarının işyükünün hafifletilmesi maksadıyla ÖVD çalışanlar için hem bir teşvik hem bir baskı unsuru olabilmektedir (VigodaGadot, 2006:78). Bu açıdan ÖVD'nin gönüllü olmakla birlikte kısmen mahalle baskısından kaynaklandığı da ifade edilebilir. Zaten ÖVD'lerin hissedilen baskılar nedeniyle yapıldığ 1 Vigoda-Gadot (2006), Vigoda-Gadot (2007) ve Bolino ve Grant (2016) tarafından ortaya konmaktadır. Buradan hareketle çalışanların çoğunlukla çalışanların isteklerinden ziyade yöneticilerin, çalışma arkadaşlarının ve bazen müşteri, tedarikçi gibi üçüncü tarafların baskılarından dolayı ÖVD gösterdikleri düşünülebilir. Nitekim çalışanların kendi istekleri ile göstermiş oldukları ekstra rol davranışları, zaman içerisinde yöneticiler ve hatta çalışma arkadaşları tarafından normal olarak karşılanmakta ve başta iyi niyet ve yardımseverlik duyguları ile başlayan söz konusu ekstra rol davranışları çalışandan rutin bir şekilde beklenmeye başlanmaktadır (Porpara, 1989).

Özellikle işveren ve yöneticiler maksatlı olarak bazı çalışanların sergilemiş oldukları ÖVD'leri tüm çalışanlardan bekler ve ister hale gelmektedir. Bir anlamda çalışanların başta iyi niyet ve kendi isteği ile göstermiş oldukları yardım severlik, centilmenlik ve politika yapımına katılım gibi iyi niyete dayanan, görevlerinin ötesinde yaptıkları işler görev tanımlarında yer alarak Zorunlu Örgütsel Vatandaşlık Davranışı (ZÖVD) haline gelmektedir (Vigoda-Gadot, 2006). Eskiden ÖVD olarak görülen özelliklerin günümüzde görev tanım formlarında yer alan ve işe alımlar dahil tüm süreçlerde aranılan nitelikler olduğu görülmektedir (Bergeron vd., 2013:836). Bu kapsamda zaman içerisinde ZÖVD, ÖVD'nin sosyal ve olumlu yapısının örgüt içerisindeki olumsuz yansıması haline dönüşebilmektedir (Porpara, 1989). ÖVD’nin örgütsel süreçler bağlamında tanınmasının ve yöneticiler tarafindan ödüllendirilmesinin zorluğu düşünüldügünde görev tanımlarında yer almasına doğru bir yönelişin haksız olmadığı da ifade edilebilir. Diğer taraftan ekstra rol davranışlarının çalışanlar tarafindan örgüte katkı sağlamak amacıyla yapılabildiği gibi kişisel imaj için ya da yöneticilerin gözünde yer edinmek için de yapılabildiği (Bolino, 1999) düşünüldüğünde, yöneticiler tarafından zorunlu hale getirilmesi de doğal karşılanabilir.

Çalışanların kendi arzuları ile sergilemiş olduğu görev tanımlarının ötesindeki yardım sever davranışları, onların örgütlerine daha çok bağlanmalarını sağlarken, örgütsel performansı da artırmaktadır (Organ ve Ryan, 1995). Diğer yandan, Bergeron (2007) ve Bergeron ve arkadaşları (2013) tarafindan ileri 
sürüldüğü gibi ÖVD'ler esasen bireysel iş performansından ödün verilmesi anlamına gelmektedir. Bireysel iş performansının ödüllendirilmesi söz konusu olduğuna göre, işle ilgili zamanı ÖVD’ye ayıran çalışanın performansının düşmesi olası olduğundan çalışanın ödül alma ve kariyer gelişimi gibi bireysel kazanımları olumsuz etkilenebilir (Bergeron, 2007:1078). Diğer taraftan Bergeron (2007) tarafından belirtildiği gibi ÖVD'ler bireysel iş performansını olumsuz etkilerken, örgütsel etkililiğe katkı sağlamaktadır. Benzer şekilde, söz konusu teoriye göre kendi irade ve istekleri dışında ZÖVD sergileyen çalışanların bireysel iş performanslarının düşük olması daha muhtemeldir. Nitekim Tepper ve arkadaşları (2004) ZÖVD'nın yüksek olduğu örgütlerde çalışanların kendilerini sömürülen ve suistimal edilen bireyler oldukları şeklinde hissetmelerine neden olduğunu ve bu durumun çalışanların bireysel iş performanslarına olumsuz yansıdığını ifade etmiştir. Vigoda-Gadot (2007) da ZÖVD'nin çalışanların iş tatminsizliği yaşayarak performans düşüklüğü göstermelerine sebep olduğunu bulgulamıştır. Ayrıca Grant (2008) ve Bolino ve Turnley (2005) çalışma arkadaşlarına yardım etmek yükümlülüğü altına giren çalışanların işyükünün artabileceğini ve stres yaşayabileceğini, bu sebeple bireysel iş performanslarının düşebileceğini ileri sürmüştür. Zaten iş performansına ayıracağı zamanın bir kısmını arkadaşlarına yardıma ayıranların performanslarının düşük olduğu da tespit edilen bulgular arasındadır (Bergeron vd., 2013). Yukarıda belirtilen kuramsal bilgiden ve daha önce yapılan çalışmalardan yola çıkarak aşağıdaki hipotez geliştirilmiştir.

H1: Çalışanların zorunlu örgütsel vatandaşlık davranışları bireysel iş performanslarını negatif etkiler.

\section{C. Örgütsel Sinizmin Bireysel İş Performansı ile İlişskisi}

Sinizm, bir dizi olumsuz örgütsel sonuçları da beraberinde getirebildiği için örgütler açısından önem atfedilmektedir (Karacaoğlu ve İnce, 2012). Sinizm özellikle örgüte bağlılığı azaltmakta, iş tatminini düşürmekte ve çalışanların örgütlerine karşı yabancılaşmasına neden olmaktadır (Dean vd, 1998). Örgütsel sinizm, çalışanın genel olarak yönetimi küçümsemesi, bencillikle suçlaması, meslektaşlarını hor görüp aşağılaması, örgüte karşı aşırı derecede olumsuz tutum içine girmesi ve örgüte karşı şüphe ve güvensizlik duymasıdır (Brandes, 1997). $\mathrm{Bu}$ şekli ile örgütsel sinizm, çalışanın örgütüne yönelik geliştirdiği olumsuzluklar neticesinde (Erdost vd., 2007), değişik disiplinlerden de beslenerek, örgüte ilişkin olumsuz duygu, tutum ve davranışlar ile inançların tamamıdır (Dean vd., 1998). Örgütsel sinizm çalışanlardaki umutsuzluk, çekingenlik ve hayal kırıklıkları ile karakterize edilmektedir (Andersson ve Batesman, 1997). Buradan hareketle örgütsel sinizmin psikolojik sözleşme kuramı çerçevesinde daha anlaşılır bir hal aldığı ifade edilebilir. Psikolojik sözleşme kuramı işveren ile çalışan arasındaki ilişkiyi beklenti ve yükümlülükler bağlamında ele almaktadır (Topcu ve Basım, 2015). Beklentileri karşılanmayan çalışanın sinik davranışlar göstermesi beklenebilir (Koçoğlu, 2014:26). Leung ve arkadaşları (2010) tarafından da belirtildiği gibi işverenin dürüst davranmadığına inanan çalışan sinik davranışlara 
M. K. Topcu, M. Beğenirbaş \& E. Turgut / Örgütsel Sinizm, Zorunlu Örgütsel Vatandaşllk Davranışlart ve İs Tatmininin Bireysel I̦S Performansına Etkilerinin Belirlenmesine Yönelik İmalat Sanayide Bir Uygulama

yönelebilmektedir. Benzer şekilde, çalışanlar çalışma koşullarını değiştirme eğilimindeki işverenlere karşı da olumsuz tutum gösterebilmekte ve sinik davranabilmektedir (Naus vd., 2007:685).

$\mathrm{Bu}$ bağlamda Dean ve arkadaşları (1998) örgütsel sinizmi; bilişsel, duyuşsal ve davranışsal olarak üç alt boyutta ele almışlardır. Örgütsel sinizmin bilişsel boyutu, organizasyonun dürüstlük ve şeffaflıktan yoksun olduğu düşüncesini ifade ederken, duyuşsal boyutu duygular ve duygusal tepkilere, davranışsal boyutu ise gözlenebilir olumsuz hareketlere işaret etmektedir (Stanley vd., 2005).

Örgütsel sinizmin belirleyicisi olarak algilanan stres, yetersiz sosyal destek, iletişim eksikliği, rol belirsizliği, rol çatışması, yönetime duyulan güvensizlik, sınırlı yönetim becerileri, yeniden yapılanmalar, ücret eşitsizlikleri ve psikolojik sözleşme ihlalleri sayılabilir (Koçoğlu, 2014:27). Diğer yandan, sinizmin sonuçları genellikle olumsuz çıktılar olarak ortaya çıkmaktadır (Bommer vd., 2005:736). Örneğin, olumsuz çıktılar arasında işten ayrılma niyeti, devamsızlık, motivasyon eksikliğii, çalışma arkadaşları ile çatışmalar ve düşük performans görülmektedir (Koçoğlu, 2014:27). Performans konusunda yapılan çalışmalarda sinik çalışanların, örgüt ve yönetim hakkındaki olumsuz düşüncelerine bağlı olarak bireysel iş performanslarında azalma tespit edilmiştir (Brown ve Cregan, 2008). Wanous ve arkadaşları (2000) da sinik çalışanların motivasyon eksikliğine bağlı olarak performans göstermediklerini belirtmektedir. Wanous ve arkadaşları (1994), Andersson ve Bateman (1997), Dean ve arkadaşları (1998) ve Byrne ve Hochwarter (2008) örgütsel sinizmin olumsuz sonuçları arasında düşük performansa yer vermektedir. Nitekim örgütsel sinizm gösteren çalışanlar ödül ve takdirden yoksun kalacağını düşünerek bireysel iş performansı göstermeye gerek kalmayacağına karar vermektedir (Chiaburu vd., 2013:187). Sinizm çalışanların yetkinliklerini sınırlandırarak, iş becerilerini kullanmalarını kısıtlayarak bireysel iş performansının azalmasına sebep olabilmektedir (Candan, 2013:189).

Sinik davranışların bireysel iş performansının azalmasına yol açması beklenti ve atıf kuramları kapsamında da açıklanabilmektedir. Beklenti kuramında beklenti bileşeni çalışanın bireysel iş performansı ile doğrudan ilişkili olduğu için iyi yönetim becerileri sinik davranışları önleyebilecektir. Diğer türlü beklentileri karşılanmayan çalışan sinik davranışlara yönelebilecektir. Atıf kuramı çerçevesinde ele alındığı da örgütsel başarısızlık çalışanlara atfedileceği için motivasyon eksikliğine neden olarak sinik davranışların ortaya çıkmasına ve performansın düşmesine neden olabilmektedir (Wanous vd., 2000:136). Yukarıda yer alan kuramsal bilgiden ve daha önce yapılan çalışmalardan yola çıkarak aşağıdaki hipotez geliştirilmiştir.

H2: Çalı̧̧anların örgütsel sinizm davranışları bireysel iş performanslarını negatif etkiler. 


\section{D. İş Tatmininin Bireysel İş Performansı ile İlişskisi}

İş tatmini, kişinin işi ile ne kadar mutlu olduğunun ifadesi (Mrayyan, 2005) veya kişinin işinden istediği ile elde ettiğini karşılaştırması sonucunda göstermiş olduğu duygusal tepkiye verilen addır (Samad, 2006). Genel anlamda iş tatmini, işin ve çalışanların isteklerinin birbirine uyduğu zaman gerçekleşen, çalışanların işlerinden duydukları hoşnutluktur (Fritzsche ve Parrish, 2005). İş tatmini çalışanların işlerine karşı gösterdikleri duygusal tepkiler şeklinde de tanımlanmaktadır (Weiss, 2002). Çalışanın işine gösterdiği duygu, olumlu ya da olumsuz olabileceğinden, bireyin iş tecrübeleri sonucunda elde ettiği olumlu ruh hali iş tatmini, çalışanın işine göstermiş olduğu olumsuz ruh hali de iş tatminsizliği olarak adlandırılabilir (Spector, 1996).

Çalışanların bireysel iş performanslarını geliştirme konusunda sıklıkla üzerinde durulan değişkenlerden birisi iş tatminidir (Akkoç vd., 2012). Örgütlerin iş tatmini sağlama gayretlerinin altında çalışanların bireysel iş performanslarını artırarak verimlilik sağlamak yatmaktadır (Candan, 2013:188). Zira iş tatmini gibi bireysel tutumların örgütsel sonuçlardan ziyade bireysel iş performansı gibi daha çok iş odaklı tutum ve davranışlara sebep olduğu belirtilmektedir (Porter vd., 1974; Wiener ve Vardi, 1980; Shore ve Martin, 1989). Iaffaldano ve Muchinsky (1985) de iş tatmini ile performans arasında sezgisel olarak kuvvetli bir ilişki olduğunun varsayıldığını ifade etmektedir. Diğer yandan, Judge ve arkadaşları (2009) da iş tatmini ve bireysel iş performansı arasındaki kuvvetli ilişkiye vurgu yapmakla birlikte ilişkinin yönünün ve bu ilişkide aracılık rolü olabilecek diğer değişkenlerin araştırılması gerektiğini ifade etmektedir. Judge ve arkadaşları (2001) yaptıkları meta analizde iş tatmini ile bireysel iş performansı arasındaki ilişkiyi inceleyen yedi farklı modeli tespit ve test etmiştir. Araştırmacılar tarafından iş tatmininin bireysel iş performansının belirleyicisi olduğu ve onu olumlu etkilediği ifade edilmektedir.

İş tatmini ile bireysel iş performansı arasındaki ilişki sosyal değişim kuramı yardımıyla açıklanabilmektedir (Loi vd., 2006). Blau (1964)'nun sosyal değişim kuramı, çalışanlar ile organizasyon arasında var olan ama net bir şekilde belirli olmayan, beklentilerle ilişkili karşılıklı yükümlülüklerden yola çıkmaktadır (Coyle-Shapiro ve Conway, 2005). Bu kurama göre, çalışanlar örgüt faaliyetlerinin kendi menfaatleri doğrultusunda faydalı olduğuna inandıkları ölçüde bireysel iş performansı göstermektedir (Rhoades ve Eisenberger, 2002). O halde çalışanların yüksek performans ile çalışabilmeleri işlerinden tatmin sağlamalarıyla mümkündür (Feldman ve Arnold, 1983; Poon, 2004). Shore ve Martin (1989) da iş tatmininin özellikle kısa dönemli performans değerlendirmelerinin asıl belirleyicisi olduğunu savunmaktadır. Yukarıda belirtilen kuramsal bilgiden ve daha önce yapılan çalışmalardan yola çıkarak aşağıdaki hipotez geliştirilmiştir.

H3: Çalışanların işlerinden duyduğu iş tatmini bireysel iş performanslarını pozitif etkiler. 
M. K. Topcu, M. Bĕgenirbaş \& E. Turgut / Örgütsel Sinizm, Zorunlu Örgütsel Vatandaşlık Davranışları ve İş Tatmininin Bireysel Iş̧ Performansına Etkilerinin Belirlenmesine Yönelik Imalat Sanayide Bir Uygulama

\section{YÖNTEM}

Araștırmanın amacı bireysel iș performansının belirleyicileri olarak ZÖVD, örgütsel sinizm ve iş tatmininin etkilerini belirlemek olarak tespit edilmiştir. $\mathrm{Bu}$ maksatla Şekil-1'de gösterilen araştırma modeli kullanılmıştır.

Şekil 1. Araştırmanın Modeli

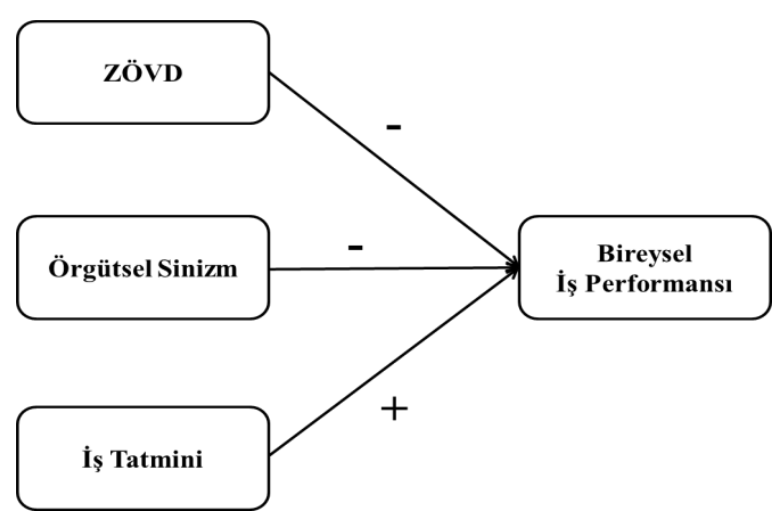

$\mathrm{Bu}$ araştırmada, korelasyonel araştırma deseni kullanılmıştır. Bu desen, ele alınan değişkenler arasındaki nedensel ilişkiyi, herhangi bir şekilde bu değişkenlere müdahale edilmeden ortaya koyma amacına yönelik olduğundan (Büyüköztürk vd., 2008), çalışmada nedensel ilişkinin test edilebileceği bir katılımc1 grubundan istifade edilmiştir. Araştırma, anılan katılımc1 grubundan, aşağıda ayrıntılı olarak açıklanan ölçeklerle toplanan verilerin SPSS 21.0 ve AMOS 16.0 programları kullanılarak yapılan analizlerle gerçekleştirilmiştir. $\mathrm{Bu}$ kapsamda, öncelikle her bir ölçeğin doğrulayıcı faktör analizi (DFA) yapılmış, daha sonra değişkenler arası korelâsyonlar ortaya konulmuş ve yapılan regresyon analizi ile hipotezler test edilmiştir. Regresyon analizine geçilmeden önce değişkenler arasında normallik, doğrusallık ve çoklu bağıntılılık olup olmadığı araştırılmıştır. Normallik için dağılımdaki verilerin gözlenen ve beklenen değerlerinin bir grafik üzerinde gösterildiği normal ihtimal grafiğine ve ayrıca normallik testi olan Kolmogorov-Smirnov testi değerlerine bakılmıştır. İhtimal grafiklerinde değerlerin bir doğru üzerinde veya etrafında toplandığı, Kolmogorov-Smirnov test değerlerinin de $\mathrm{p}<0,05$ anlamlılık düzeyinde olduğu; bu nedenle tüm verilerin normal dağıldığı görülmüştür (Büyüköztürk, 2007).

\section{A. Katılımcilar}

Araştırmanın katılımcılarını, Ankara Sanayi Odasına (ASO) üye firmalarda çalışan ve ASO'da 1.1.2016-1.3.2016 tarihleri arasında yönetim ve insan kaynakları konusunda eğitim almaya gelmiş çalışanlar oluşturmaktadır. Söz 
konusu eğitimi almaya gelmiş 187 kişinin araştırmanın kuramsal bağlamına uygun (convenience) bir kitle olmasından hareketle, anket formları dağıtılarak, formların gönüllülük esasıyla, araştırmacıların nezareti altında doldurulması sağlanmıştır. Araştırmanın amacı ele alınan değişkenler arası nedensel ilişkileri açıklamak olduğundan, ASO'ya bağlı firmalarda çalışanlar bu beklentiyi karşılamaktadırlar. Bu anketlerin 165 'i geri toplanabilmiştir. Eksik ve ciddi doldurulmadığı belirlenen 15 anket ile uç analizi sonucunda 12 anket değerlendirme dışında bırakılmış ve analizler 138 anket üzerinde yürütülmüştür. Katılımcıların yaş ortalaması 33,74 (ss. 8,07), 56'sı kadın (\%40,6), 82'si erkektir $(\% 59,4)$. Yine katılımcıların 81'i evli (\%58,7), 57'si bekardır (\%41,3).

\section{B. Veri Toplama Araçları}

Veriler, beşli Likert (1=Kesinlikle katılmıyorum, 5=Kesinlikle katılıyorum) formunda hazırlanan, bireysel iş performansı, ZÖVD, iş tatmini ve örgütsel sinizm ölçekleri ile elde edilmiştir. Ölçeklerin tamamı daha önce geçerlik ve güvenirlik çalışmaları yapılmış olduğundan doğrulayıcı faktör analizi yapılarak yapısal geçerlikleri test edilmiş ve Cronbach Alfa katsayıları hesaplanarak güvenirlik testleri yapılmıştır.

\section{(1) Bireysel İş Performansı Ölçeği}

Çalışanların bireysel iş performansının ölçülmesinde; Kirkman ve Rosen (1999) ve Sigler ve Pearson (2000) tarafından kullanılan bireysel iş performansı ölçeği kullanılmıştır. Ölçek tek boyutlu olup, "İşimde göstermiş olduğum performans düzeyim yüksektir", "İş hedeflerime fazlasıyla ulaşırım" gibi ifadeleri içeren 4 maddeden oluşmaktadır. Ölçeğin iç tutarlılık düzeyinin kabul edilebilir düzeyde $(0,782)$ olduğu görülmektedir (Özdamar, 1999: 522). Ölçeğin faktör yapısını doğrulamak üzere doğrulayıcı faktör analizi yapılmış, analiz sonuçları $\left(\Delta \chi^{2} / \mathrm{sd}=0,49, \mathrm{RMSEA}=0,009, \mathrm{GFI}=0,98, \mathrm{CFI}=0,99\right.$, AGFI=0,97) ölçeğin tek boyutlu ve dört sorulu yapısını doğrulamıştır (Baron ve Kenny, 1986).

\section{(2)Zorunlu Örgütsel Vatandaşlık Davranışı Ölçeği}

ZÖVD, Vigoda-Gadot'un (2007) geliştirdiği tek boyutlu bir ölçek olup, "Bu kurumda yöneticiler çalışanlara resmi görevlerinin ötesinde ekstra faaliyetlerde bulunmaları için baskı uygular", "Görevimi yaparken, resmi iş gereklerimin ötesinde çaba harcamam için bir bask1 olduğunu hissediyorum" şeklinde 5 maddeden oluşmaktadır. Ölçeğin iç tutarlılık düzeyinin kabul edilebilir düzeyde $(0,834)$ olduğu görülmektedir (Özdamar, 1999: 522). Ölçeğin faktör yapısını doğrulamak üzere doğrulayıcı faktör analizi yapılmış, analiz sonuçları $\left(\Delta \chi^{2} / \mathrm{sd}=1,14, \mathrm{RMSEA}=0,032, \mathrm{GFI}=0,98, \mathrm{CFI}=0,99, \mathrm{AGFI}=0,95\right)$ ölçeğin tek boyutlu ve beş faktörlü yapısını doğrulamıştır (Baron ve Kenny, 1986).

\section{(3) Örgütsel Sinizm Ölçeği}

Brandes ve arkadaşları (1999) tarafından geliştirilen Örgütsel Sinizm Ölçeği üç alt boyut ve 13 maddeden oluşmaktadır. Bilişsel boyut "Çalıştığım kurumda, söylenenler ile yapılanların farklı olduğuna inanıorum" ş̧eklinde 5 maddeden, duyuşsal boyut "Çalıştığım kurumu düşündükçe sinirlenirim" şeklinde 
M. K. Topcu, M. Beğenirbaş \& E. Turgut / Örgütsel Sinizm, Zorunlu Örgütsel Vatandaşllk Davranışlart ve İs Tatmininin Bireysel I̦S Performansına Etkilerinin Belirlenmesine Yönelik İmalat Sanayide Bir Uygulama

4 maddeden ve davranışsal boyut ise "Başkalarıyla, çalıştı̆̆ım kurumdaki işlerin nasıl yürütüldüğ̈̈ hakkında konuşurum” şeklinde 4 maddeden oluşmaktadır. Ölçeğin faktör yapısını doğrulamak için yapısal eşitlik modeli kullanılarak ilişkisiz, tek faktörlü, birinci düzey ve ikinci düzey çok faktörlü modellere DFA yapılmıştır. Tablo 1'de yer alan DFA sonuçları incelendiğinde, ölçeğin ikinci düzey çok faktörlü modelde en iyi uyum iyiliği sergilediği görülmektedir (Baron ve Kenny, 1986). Ölçeğin iç tutarlılık düzeyinin 0,881 (bilişsel boyut 0,799 ; duyuşsal boyut 0,890; davranışsal boyut 0,730) ve kabul edilebilir düzeyde olduğu görülmektedir (Özdamar, 1999: 522).

Tablo1. Örgütsel Sinizm Ölçeğinin DFA Sonuçları

\begin{tabular}{lccccc}
\hline Model & $\Delta \boldsymbol{\chi}^{2} / \mathbf{s d}$ & RMSEA & CFI & GFI & AGFI \\
\hline İlişkisiz model & 4,183 & 0,089 & 0,84 & 0,87 & 0,82 \\
Tek faktörlü & 2,389 & 0,079 & 0,84 & 0,87 & 0,86 \\
Birinci düzey çok faktörlü & 3,149 & 0,083 & 0,90 & 0,85 & 0,81 \\
Íkinci düzey çok faktörlü & $\mathbf{1 , 6 8}$ & $\mathbf{0 , 0 7 1}$ & $\mathbf{0 , 9 7}$ & $\mathbf{0 , 9 2}$ & $\mathbf{0 , 9 1}$ \\
\hline
\end{tabular}

\section{(4) İs Tatmini Ölçeği}

İşletmelerde algilanan iş tatmini düzeyini belirlemek üzere Judge ve arkadaşları (2009) tarafindan geliştirilen tek boyutlu ve 5 maddeli ölçek kullanılmıştır. "İşimden tatmin olduğumu hissediyorum", "İşsimi yaparken, gün hiç bitmeyecekmiş gibi geliyor" ölçek maddelerinin bazılarıdır. Ölçeğin bir maddesindeki faktör yükü düşük olduğundan ölçekten çıkarılmıştır. Ölçeğin 4 maddeli olarak iç tutarlılık düzeyinin kabul edilebilir düzeyde $(0,832)$ olduğu görülmektedir (Özdamar, 1999: 522). Ölçeğin faktör yapısını doğrulamak üzere DFA yapılmış, analiz sonuçları $\left(\Delta \chi^{2} / \mathrm{sd}=1,70, \quad \mathrm{RMSEA}=0,072 \quad \mathrm{GFI}=0,98\right.$, $\mathrm{CFI}=0,98$, AGFI=0,92) ölçeğin tek boyutlu ve dört sorulu yapısını doğrulamıştır (Baron ve Kenny, 1986).

\section{BULGULAR}

Değişkenler arası ilişkileri ortaya koymak üzere boyutlar arası korelasyonlar incelenmiş, bireysel iş performansı ile ZÖVD, örgütsel sinizm ve iş tatmini arasındaki etkiyi ortaya koymak üzere regresyon analizi yapılmıştır. Değişkenler arası ilişkiyi belirlemek üzere yapılan korelasyon analizi sonuçları Tablo-2'de gösterilmektedir. Değişkenler arasında genel olarak orta düzeyde ilişki olduğu anlaşılmaktadır. Değişkenler arasındaki en yüksek ilişkinin örgütsel sinizm ile iş tatmini arasında negatif yönlü olduğu görülmektedir ( $\mathrm{r}=-.459$, $\mathrm{p}<0.01)$. Ayrıca, ZÖVD ile örgütsel sinizm arasında da pozitif yönlü nispeten yüksek düzeyde ilişki tespit edilmiştir $(\mathrm{r}=.441, \mathrm{p}<0.01)$. 
Tablo 2. Değişkenler Arası Korelasyon Değerleri

\begin{tabular}{lccccc}
\hline Değişkenler & & $\mathbf{( 1 )}$ & $\mathbf{( 2 )}$ & $\mathbf{( 3 )}$ & $\mathbf{( 4 )}$ \\
\hline$\dot{I}_{\text {Ş Performansı }}$ (1) & 1 & & & \\
ZÖVD & $\mathbf{( 2 )}$ &,$- 168^{*}$ & 1 & & \\
Örgütsel Sinizm & $\mathbf{( 3 )}$ & $-.208^{* *}$ & $.441^{* *}$ & 1 & \\
$\dot{I}_{S}$ Tatmini & $\mathbf{( 4 )}$ & $.337^{* *}$ & $-.199^{*}$ & $-.459^{* *}$ & 1 \\
\hline
\end{tabular}

Açıklamalar: ** $\mathrm{p}<0,01 ; * \mathrm{p}<0,05$

Bireysel iş performansı üzerinde ZÖVD, örgütsel sinizm ve iş tatmininin etkisini tespit edebilmek için regresyon analizi yapılmış ve analiz sonuçları Tablo-3'te gösterilmiştir. Regresyon analizleri incelendiğinde, korelasyon değerleri ile uyumlu olduğu, bireysel iş performansının çalışmanın bağımsız değişkenleri tarafından anlamlı olarak yordandığı görülmektedir. Bu kapsamda, bireysel iş performansı ZÖVD ve örgütsel sinizm tarafından negatif, iş tatmini tarafından ise pozitif olarak yordanmaktadır. Bu bulgular, çalışmada geliştirilen her üç hipotezin de kabul edildiğini göstermektedir.

Tablo 3. Regresyon Katsayıları

\begin{tabular}{|c|c|c|c|}
\hline \multirow[t]{2}{*}{ Değişkenler } & \multicolumn{3}{|c|}{ Bireysel İş Performansı } \\
\hline & beta & $\mathrm{t}$ & $\mathrm{p}$ \\
\hline Sabit & & 7,059 &, 000 \\
\hline$Z \ddot{O V D}$ &,- 147 & ,983 &, 021 \\
\hline Örgütsel Sinizm &,- 193 & 1,499 &, 000 \\
\hline İş Tatmini &, 422 & 4,700 & ,000 \\
\hline
\end{tabular}

Ayrıca, çalışmada ele alınan demografik değişkenlerin (yaş, cinsiyet, medeni durum) diğer değişkenler üzerine etkilerini ortaya koymak maksadıyla iki ortalama arasında anlamlı fark olup olmadığını test etmek için bağımsız örneklem t- testi, ikiden fazla ortalamaların karşılaştırılması için tek yönlü varyans analizi (ANOVA) yapılmıştır. Yapılan analiz sonuçları neticesinde tüm değişkenler (bireysel iş performans1, ZÖVD, örgütsel sinizm, iş tatmini) ile çalışmada ele alınan demografik değişkenler arasında istatistiksel olarak anlamlı farklılıklara rastlanılmamıştır.

\section{SONUÇ VE DEĞERLENDİRME}

İşletmelerin başarısındaki en önemli unsurlardan birisi insan faktörüdür. Son dönemde işletmeler için beşeri sermayenin sürdürülebilir rekabet avantaj1 sağlayan temel faktör olduğu tartış1maz bir şekilde kabul edilmiştir. İşletmelerin 
M. K. Topcu, M. Beğenirbaş \& E. Turgut / Örgütsel Sinizm, Zorunlu Örgütsel Vatandaşllk Davranışlart ve İs Tatmininin Bireysel I̦S Performansına Etkilerinin Belirlenmesine Yönelik İmalat Sanayide Bir Uygulama

daha verimli ve etkili olabilmeleri, rekabet avantajı sağlayabilmeleri çalışanlarının bireysel iş performansına bağlıdır. Bu nedenle, bireysel iş performansına neden olan faktörlerin belirlenmesi beşeri sermayenin yönetimi açısından önemlidir.

$\mathrm{Bu}$ doğrultuda, bu çalışma örgütler açısından işgücü verimliliğinin temel göstergesi olan bireysel iş performansının öncülleri arasında değerlendirilen ancak alanyazında çok sık rastlanmayan zorunlu örgütsel vatandaşlık davranışı ve örgütsel sinizm ile çok sık ele alınan iş tatmininin çalışanların bireysel iş performansları üzerindeki etkilerini ortaya koymak amacı ile yapılmıştır.

Çalışmanın sonuçlarına bakıldığında genel olarak; çalışanların ZÖVD sergilemeleri veya söz konusu davranışı gösterme beklentileri onların üzerinde bir bask1 ve sömürülme hissi uyandırdığından bireysel iş performanslarını olumsuz yönde etkilemektedir. Bu bulgu ZÖVD ve performans arasında yapılan benzer çalışmalarla (Tepper vd., 2004; Vigoda-Gadot, 2007) örtüşmektedir.

Çalışmada örgütsel sinizmin de çalışanların bireysel iş performanslarına olumsuz yönde yansımalar yaptığı ve onların örgütteki sinik davranışlarının bireysel iş performanslarını negatif olarak etkilediği tespit edilmiştir. $\mathrm{Bu}$ tespit alanyazındaki çalışmalarla (Andersson ve Bateman, 1997; Brown ve Cregan, 2008; Chiaburu vd., 2013; Wanous vd.,1994) örtüşmekte ve onlar1 desteklemektedir.

Son olarak çalışmada işinde ve yaptığı görevde tatmin yaşayan çalışanların söz konusu tatmin duygularının bireysel iş performanslarına da olumlu olarak yansıdığı sonucuna ulaşılmıştır. Bu sonuç da daha önceki benzer araştırmalarla (Akkoç vd., 2012; Feldman ve Arnold, 1983; Poon, 2004; Iaffaldano ve Muchinsky, 1985) örtüşmekte ve onları desteklemektedir.

$\mathrm{Bu}$ kapsamda elde edilen sonuçlar 1şı̆̆ında çalışma, bireylerin gösterecekleri bireysel iş performansları açısından iş yerindeki ZÖVD'ler, örgütteki sinik tutum ve davranışlar ile çalışanların yaptıkları işten haz duymaları ve tatmin olmalarına vurgu yapması açısından önem arz etmektedir.

$\mathrm{Bu}$ sonuçlar aynı zamanda örgütlerin yönetim kademeleri ile özellikle insan kaynakları birimleri veya sorumluları için, çalışanların bireysel iş performanslarının yönetilmesinde ve diğer yönetim süreçlerinde dikkat edilmesi gereken hususlar ve değişkenlere vurgu yapması bakımından da önemlidir. Pozitif örgütsel davranışların çalışanların davranış ve tutumları üzerindeki etkileri sıklıkla araştırılırken, ZÖVD ve örgütsel sinizm gibi diğer örgütsel davranışların etkilerinin araştırılması pozitif psikoloji bağlamında ayrı bir öneme sahiptir. Örgütler için sürdürülebilir rekabet avantajı sağlayacak beşeri sermayeye ilişkin yapılan insan kaynakları uygulamalarında temel olan görev tanım formlarının hazırlanmasında ZÖVD'lere gereksiz yer verilmemesi bireysel iş performansını olumlu yönde etkileyecektir. Uygulamaların içerisindeki diğer temel bir uygulama olan performans yönetiminde göstergeleri belirlerken örgütsel sinizme yer verilmeyecek tarzda bir yaklaşım benimsenmesi verimliliği artırabilecektir. 
$\mathrm{Bu}$ çalışmanın sonuçları neticesinde ileride yapılacak araştırmalar ve uygulamalara yönelik birkaç öneri sunulabilir. Bu kapsamda çalışma, farklı öncül değişkenler ile zenginleştirilerek yapılabileceği gibi, farklı katılımcıların ele alındığı örneklem, meslek grupları ve bölgesel farklılıkları da içerecek şekilde daha detaylı olarak ele alınabilir. Ayrıca bu çalışmada öncül değişkenlerin bireysel iş performansı üzerindeki doğrudan etkileri ortaya konmuştur. Bu alanda çalışacak araştırmacıların değişkenler arasındaki doğrudan ve dolaylı ilişkileri analiz ederek değişkenlerin aracılık veya düzenleyicilik rollerini belirleyecek bütüncül bir modeli çalışmaları önerilebilir. Bir diğer çalışma alanı ise ÖVD'lere veya ZÖVD’lere ayrılan zamanın kontrol değişkeni olarak ele alınması olabilir. Zira bireysel iş performansı ile ikame durumunda bulunan ÖVD'lerin görev tanım formlarında yer alması performans değerlendirmesinin bir parçası haline gelmesi anlamı taşımaktadır. Ancak bireysel iş performansının olumsuz etkilenmesini önlemek için ölçümlerin daha uygun yapılması gerekmektedir. Bunun da ancak ZÖVD olarak zamanın kontrol altına alınması ile mümkün olabileceği düşünülebilir.

\section{KAYNAKÇA}

Akkoç, İ., Çalışkan, A., Turunç, Ö. (2012). Örgütlerde Gelişim Kültürü ve Algılanan Örgütsel Desteğin İş Tatmini ve İş Performansına Etkisi: Güvenin Aracılık Rolü. Yönetim ve Ekonomi, 19(1), 105-135.

Andersson, L.M., Bateman, T.S. (1997). Cynicism in the Workplace: Some Causes and Effects. Journal of Organizational Behavior, 18, 449 - 469.

Baron, R.M., Kenny, D.A. (1986). The Moderator Mediator Variable Distinction in Social Psychological Research: Conceptual, Strategic, and Statistical Considerations, Journal of Personality and Social Psychology, 51, 1173-1182.

Barrick, M.R. ve Mount, M.K. (1991). The Big Five Personality Dimensions and Job Performance: A Meta-analysis. Personnel Pychology, 44 (1), 1-26.

Bergeron, D.M. (2007). The potential paradox of organizational citizenship behavior: Good citizens at what cost? Academy of Management Review, 32, 1078-1095.

Bergeron, D.M., Shipp, A.J., Rosen, B., Furst, S.A. (2013). Organizational citizenship behavior and career outcomes: The cost of being a good citizen. Journal of Management, 39, 958-984.

Blau, P. (1964). Exchange and Power in Social Life. New York: Wiley.

Bolino, M.C. (1999). Citizenship and impression management: Good soldiers or good actors? Academy of Management Review, 24, 82-98.

Bolino, M.C., Grant, A.M. (2016). The bright side of being prosocial at work, and the dark side, too: a review and agenda for research on other-oriented motives, behavior, and impact in organizations. Academy of Management Annals, 10(1), 599-670.

Bolino, M.C., Turnley, W.H. (2005). The personal costs of citizenship behavior: the relationship between individual initiative and role overload, job stress, and work-family conflict. Journal of Applied Psychology, 90(4), 740.

Bommer, W.H., Rich, G.A.,Rubin, R.S. (2005). Changing Attitudes About Change: Longitudinal Effects of Transformational Leader Behavior on Employee Cynicism About Organizational Change.Journal of Organizational Behavior, 26, 733-753.

Borman, W. C., Motowidlo, S. J. (1993). Expanding The Criterion Domain to Include Elements of Contextual Performance, (Der.), Schmitt, N. ve Borman, W.C. Personnel Selection in Organizations, San Francisco, Ca: Jossey-Bass.

Brandes, P.M. (1997).Organizational Cynicism: Its Nature, Antecedents, and Consequences. Unpublished Doctoral Dissertation. The University of Cincinnati. 
M. K. Topcu, M. Bĕgenirbaş \& E. Turgut / Örgütsel Sinizm, Zorunlu Örgütsel Vatandaşlık Davranışları ve İş Tatmininin Bireysel İş Performansına Etkilerinin Belirlenmesine Yönelik İmalat Sanayide Bir Uygulama

Brandes, P., Dharwadkar, R., Dean, J.W. (1999). Does Organizational Cynicism Matter? Employee and Supervisor Perspectives on Work Outcomes. Eastern Academy of Management Proceedings, $150-153$.

Brown, M., Cregan, C. (2008). Organizational Change Cynicism: The Role of Employee Involvement. Human Resource Management, 47(4), 667-686.

Büyüköztürk, Ş. (2007). Sosyal Bilimler İçin Veri Analizi El Kitabı. Ankara: Pegem Yayıncılık.

Büyüköztürk, Ş., Çakmak, E.K., Akgün, Ö.E., Karadeniz, Ş., Demirel, F. (2008). Bilimsel Araştırma Yöntemleri, Geliştirilmiş 2. Baskı, Ankara: Pegem Akademi.

Byrne, Z. S., Hochwarter, W. A. (2008). Perceived organizational support and performance: Relationships across levels of organizational cynicism. Journal of Managerial Psychology, 23(1), 54-72.

Campbell, J. P., McCloy, R. A., Oppler, S. H., Sager, C. E. (1993). A theory of performance: In N. Schmitt ve WC Borman (Eds.), Personnel Selection in Organizations, 35-70. San Francisco: Jossey-Bass.

Candan, H. (2013). Örgütsel Sinizm ve İşgören Performansına Olası Etkileri. Kahramanmaraş Sütçü Imam Üniversitesi İktisadi ve İdari Bilimler Fakültesi Dergisi, 3(1), 181-194.

Charbonnier-Voirin, A., Roussel, P. (2012). Adaptive performance: A new scale to measure individual performance in organizations. Canadian Journal of Administrative Sciences, 29(2), 280-293.

Chiaburu, D.S., Peng, A.C., Oh, I.S., Banks, G.C., Lomeli, L.C. (2013). Antecedents and consequences of employee organizational cynicism: A meta-analysis. Journal of Vocational Behavior, 83(2), 181-197.

Coffeng, J. K., Hendriksen, I. J., Duijts, S. F., Twisk, J. W., van Mechelen, W., Boot, C. R. (2014) Effectiveness of a combined social and physical environmental intervention on presenteeism, absenteeism, work performance, and work engagement in office employees. Journal of Occupational and Environmental Medicine, 56(3), 258-265.

Colquitt, J. A., Scott, B. A., Rodell, J. B., Long, D. M., Zapata, C. P., Conlon, D. E., Wesson, M. J. (2013). Justice at the millennium, a decade later: A meta-analytic test of social exchange and affect-based perspectives. Journal of Applied Psychology, Vol. 98, No. 2, 199-236.

Cote, S., Miners, C.T. H. (2006). Emotional intelligence, cognitive intelligence, and job performance. Administrative Science Quarterly, 51(1), 1-28.

Coyle-Shapiro, J.A-M., Conway, N. (2005). Exchange Relationships: Examining Psychological Contracts and Perceived Organizational Support. Journal of Applied Psychology, 90(4), 774-781.

Cropanzano, R., James, K., Konovsky, M.A. (1993). Dispositional affectivity as a predictor of work attitudes and job performance. Journal of Organizational Behavior, 14(6), 595-606.

Dean, J.W., Brandes, P., Dharwadkar, R. (1998). Organizational Cynicism. Academy of Management Review, 23(2), 341-352.

Erdost, E.H., Karacaoğlu, K., Reyhanoğlu, M. (2007). Örgütsel Sinizm Kavramı ve İlgili Ölçeklerin Türkiye'deki Bir Firmada Test Edilmesi.15. Ulusal Yönetim ve Organizasyon Kongresi Bildiriler Kitabl, Sakarya Üniversitesi, 514-524.

Feldman, C.D., Arnold, J.H. (1983).Managing Individual and Group Behavior in Organization. Auckland: Mc.Graw-Hill.

Fritzsche, B.A., Parrish, T.J. (2005).Theories and Research on Job Satisfaction, Career Development and Counseling: Putting Theory and Research To Work. Hoboken, NJ: Wiley.

Grant, A. M. (2008). Does intrinsic motivation fuel the prosocial fire? Motivational synergy in predicting persistence, performance, and productivity. Journal of Applied Psychology, 93, $48-58$.

Hurtz, G.M., Donovan, J.J. (2000). Personality and job performance: The big five revisited. Journal of Applied Psychology, 85(6), 869. 
Iaffaldano, M.T., Muchinsky, P.M. (1985). Job satisfaction and job performance: A metaanalysis. Psychological Bulletin, 97(2), 251.

Judge, T.A., Thoresen, C.J., Bono, J. E., Patton, G.K. (2001). The job satisfaction-job performance relationship: A qualitative and quantitative review. Psychological Bulletin, 127 (3), 376407.

Judge, T. A., Rodell, J. B., Klinger, R. L., Simon, L. S., Crawford, E. R. (2013). Hierarchical representations of the five-factor model of personality in predicting job performance: integrating three organizing frameworks with two theoretical perspectives. Journal of Applied Psychology, 98, 6, 875-925.

Judge, T.A., Woolf, E.F., Hurst, C. (2009). Is Emotional Labor More Difficult For Some Than For Others? A Multilevel, Experience-Sampling Study. Personnel Psychology, 62(1), 57-88.

Kirkman, B.L., Rosen, B. (1999). Beyond Self- Management: Antecedents and Consequences of Team Empowerment. Academy of Management Journal, 42(1), 58-74.

Kohli, A. (1985). Some Unexplored Supervisory Behaviors and Their Influence on Salespeople's Role Clarity, Specific Self Esteem, Job Satisfaction and Motivation. Journal of Marketing Research, 22, 424-433.

Kacmar, K.M., Collins, B.J., Harris, K.J., Judge, T.A. (2009). Core self-evaluations and job performance: The role of the perceived work environment. Journal of Applied Psychology, 94(6), 1572.

Kaleem, M. M., Jabeen, B., Twana, M. J. (2013). Organizational Justice in Performance Appraisal System: Impact on Employees Satisfaction and Work Performance. Studies, 2(2), 28-37.

Kaplan, S., Bradley, J. C., Luchman, J. N., Haynes, D. (2009). On the role of positive and negative affectivity in job performance: A meta-analytic investigation. Journal of Applied Psychology, 94(1), 162-176.

Karacaoğlu, K., İnce, F. (2012). Brandes, Dharwadkar ve Dean'in (1999) Örgütsel Sinizm Ölçeği Türkçe Formunun Geçerlilik ve Güvenilirlik Çalışması: Kayseri Organize Sanayi Bölgesi Örneği. Business and Economics Research Journal, 3(2), 77 - 92.

Koçoğlu, M. (2014). Cynicism as a Mediator of Relations between Job Stress and Work Alienation: A Study from a Developing Country-Turkey. Global Business and Management Research, 6(1), 24-36.

Konovsky, M.A., Cropanzano, R. (1991). Perceived Fairness of Employee Drug Testing as a Predictor of Employee Attitudes and Job Performance. Journal of Applied Psychology, 76(5), 698.

Koopmans, L., Berhnaards, C.M., Hildebrandt, V.H., Vet, H.C.W., Berk, A.J. (2014). Construct validity of the individual work performance questionnaire. Journal of Occupational and Environmental Medicine, 56(3), 154-171.

Leung, K., Ip, O. K., Leung, K. K. (2010). Social cynicism and job satisfaction: A longitudinal analysis. Applied Psychology, 59(2), 318-338.

Loi, R., Hang-Yue, N., Foley, S. (2006). Linking Employees' Justice Perceptions to Organizational Commitment and Intention to Leave: The Mediating Role of Perceived Organizational Support. Journal of Occupational and Organizational Psychology, 79, 101-120.

Macovei, C. M. (2016). Counterproductive Behaviors and Work Performance in Military Organization. In International Conference Knowledge-Based Organization, Vol. 22, No. 2, 444-450.

Morillo, C.R. (1990). The Reward Event and Motivation. The Journal of Philosophy, Vol. 87, No.4, 169-186.

Mrayyan, M. T. (2005). Nurse Job Satisfaction and Retention: Comparing Public to Private Hospitals in Jordan.Journal of Nursing Management, 13, 40-50.

Muldoon, J., Kisamore, J. L., Liguori, E. W., Jawahar, I.M., Bendickson, J. (2017). Moderators of the personality-performance relationship: An investigation of job meaning and autonomy, Personnel Review, Vol. 46 Issue: 3, 474-489. 
M. K. Topcu, M. Bĕgenirbaş \& E. Turgut / Örgütsel Sinizm, Zorunlu Örgütsel Vatandaşlık Davranışları ve İş Tatmininin Bireysel İş Performansına Etkilerinin Belirlenmesine Yönelik İmalat Sanayide Bir Uygulama

Naus, F., Van Iterson, A., Roe, R. (2007). Organizational cynicism: Extending the exit, voice, loyalty, and neglect model of employees' responses to adverse conditions in the workplace. Human Relations, 60(5), 683-718.

Organ, D.W. (1988). Organizational citizenship behavior: The good soldier syndrome. Lexington, MA: Lexington Books.

Organ, D.W., Konosky, M. (1989). Cognitive versus affective determinants of organizational citizenship behavior. Journal of Applied Psychology, 74, 157-164.

Organ, D.W., Ryan, K.A. (1995). Meta-Analytic Review of Attitudinal And Dispositional Predictors Of Organizational Citizenship Behavior. Personnel Psychology, 48, 775-82.

Özdamar, K. (1999). Paket programlar ile istatistiksel veri analizi. Eskişehir: Kaan Kitabevi.

Peterson, S. J., Luthans, F., Avolio, B. J., Walumbwa, F. O., Zhang, Z. (2011). Psychological capital and employee performance: A latent growth modeling approach. Personnel Psychology, 64(2), 427-450.

Poon, J.M.L. (2004). Effects of Performance Appraisal Politics on Job Satisfaction and Turnover Intention. Personel Review, 33(3), s. 322-334.

Porpara, D.V. (1989). Four concepts of social structure.Journal for the Theory of SocialBehavior, $19,195-211$.

Porter, L. W., Steers, R. M., Mowday, R. T., Boulian, P. V. (1974). Organizational commitment, job satisfaction, and turnover among psychiatric technicians. Journal of Applied Psychology, 59(5), 603-609.

Rhoades, L., Eisenberger, R. (2002). Perceived Organizational Support: A Review of the Literature. Journal of Applied Psychology, 87, 698-714.

Rich, B.L., Lepine, J.A., Crawford, E.R. (2010). Job Engagement: Antecedents and Effects on Job Performance. Academy of Management Journal, 53(3), 617-635.

Rotundo, M., Sackett, P. R. (2002). The Relative Importance of Task, Citizenship, and Counterproductive Performance to Global Ratings of Job Performance: A Policy Capturing Approach. Journal of Applied Psychology, 87, 66-80.

Rousseau, D.M., Mclean P.J. (1993). The Contracts of Individuals and Organizations.Research in Organizational Behavior, 15, 1-43.

Sackett, P.R. (2002). The Structure of Counter Productive Work Behaviors: Dimensionality and Relationships with Facets of Job Performance. International Journal of Selection and Assessment, 10(1), 5-11.

Samad, S. (2006). Predicting Turnover Intentions: The Case of Malaysian Government Doctors. The Journal of American Academy of Business, 8(2), 113-119.

Shan, S., Ishaq, H. M., Shaheen, M. A. (2015). Impact of organizational justice on job performance in libraries: mediating role of leader-member exchange relationship. Library Management, 36(1/2), 70-85.

Shore, L.M., Martin, H.J. (1989). Job satisfaction and organizational commitment in relation to work performance and turnover intentions. Human relations, 42(7), 625-638.

Sigler, T.H., Pearson, C.M. (2000). Creating an Empowering Culture: Examining the Relationship between Organizational Culture and Perceptions of Empowerment. Journal of Quality Management, 5, 27-52.

Spector, P.E. (1996). Industrial and Organizational Psychology: Research and Practice. USA: John Wiley \& Sons.

Stanley, D., Meyer, J., Topolnytsky, L. (2005). Employee Cynicism and Resistance to Organizational Change.Journal of Business and Psychology, 19(4), 429-459.

Tepper, B.J., Hoobler, J., Duffy, M.K., Ensley, M.D. (2004). Moderators of the relationship between coworkers' organizational citizenship behavior and fellow employees' attitudes. Journal of Applied Psychology, 89, 455-465.

Tett, R.P., Jackson, D.N., Rothstein, M. (1991). Personality measures as predictors of job performance: A meta-analytic review. Personnel Psychology,44(4), 703-742. 
Topcu, M.K. ve Basım, H.N. (2015). Kavramsal bağlamı ve olası tartışma alanlarıyla psikolojik sözleşme: Bir gözden geçirme çalışması. Eskişehir Osmangazi Üniversitesi Sosyal Bilimler Dergisi, 16 (2), 83-103.

Vigoda-Gadot, E. (2006). Compulsory citizenship behavior: Theorizing some dark sides of the good soldier syndrome in organizations. Journal for the Theory of Social Behaviour, 36(1), 77 93.

Vigoda-Gadot, E. (2007). Redrawing the Boundaries of OCB? An Empirical Examination of Compulsory Extra-Role Behavior in the Workplace. Journal of Business and Psychology, 21(3),377-405.

Viswesvaran, C., Ones, D.S. (2000). Perspectives on Models of Job Performance. International Journal of Selection and Assessment, 8(4), 216-226.

Wang, Y. (2011). A high-order performance framework: content, structure and personality antecedents, Doctoral dissertation, University of Sheffield.

Wang, H. J., Lu, C. Q., Siu, O. L. (2015). Job insecurity and job performance: The moderating role of organizational justice and the mediating role of work engagement. Journal of Applied Psychology, 100(4), 1249-1258.

Wanous, J.P.,Reichers, A.E., Austin, J.T. (1994). Organizational Cynicism: An Initial Study.Academy of Management Best Papers Proceedings, 269-273.

Wanous, J.P., Reichers, A.E. ve Austin, J.T. (2000). Cynicism about organizational change measurement, antecedents, and correlates. Group \& Organization Management, 25(2), $132-153$.

Weiss, H.M. (2002). Deconstructing Job Satisfaction Seperating Evaluations, Beliefs and Affective Experiences. Human Resource Management Review, 12, 173-194.

Wiener, Y., Vardi, Y. (1980). Relationships between job, organization, and career commitments and work outcomes-An integrative approach. Organizational Behavior and Human Performance, 26(1), 81-96.

Wright, T.A., Cropanzano, R. (1998). Emotional Exhaustion as a Predictor of Job Performance and Voluntary Turnover. Journal of Applied Psychology, 83(3), 486-493.

Wright, T. A., Hobfoll, S. E. (2004). Commitment, psychological well-being and job performance: An examination of conservation of resources (COR) theory and job burnout. Journal of Business and Management, 9(4), 389-406.

\section{SUMMARY}

This study researches effects of compulsory organizational citizenship behavior, organizational cynicism, and job satisfaction on employees' individual work performance. Quality and rapid change in contemporary business world apply a great stress on organizations. The stress results in diversification of knowledge, skills, and abilities of managers and employees, and rebounds an increase in individual work performance. It is obvious that high performance be expected in the following years. Hence, ensuring that all factors and variables contributing to high performance play a role in the organizational structure and functions becomes a must for the success. To this end, individual work performance as one of main points and determining factors in human resource management applications, from acquisition to firing, is attached a great significance.

Individual work behavior, therefore, is one of organizational issues frequently researched. However, to our best knowledge, it is not common to find studies on the effects of compulsory citizanship behavior and organizational 
cynicism. Toward this end, this study is designed to identify the effect of both and job satisfaction as determinants on individual work performancein a sample of 138 trainees employed in the manifacturing firms, which are members of Ankara Chamber of Industry.

Correlation analysis and regression analysis are employed to determine the relations and the effects between the variables, relatively, whilst confirmatory factor analysis is preferred for validating scales. Findings reveal that there is a negative effect of compulsory organizational citizenship behavior and organizational cynicism on individual work performance while the effect of job satisfaction is positive. 